\title{
Physico-Chemical Analysis of Polluted Vaalankulam Fresh Water Pond
}

\author{
Rini Christina. A*, Sarani. S**, Vinitha. $\mathrm{M}^{* * *}$ \\ Department of Environmental Engineering, Park College of Technology, \\ Coimbatore
}

\begin{abstract}
The present study deals with the water pollution caused at Vaalankulam by sewage disposal and other effluents in Ukkadam of Coimbatore district of Tamil Nadu. This is a rich source of fresh water, but has been polluted by sewage disposals to such an extent that no part of water can be used for any purpose. The study of some physiochemical properties reveals that treatment of this polluted water is essential otherwise it will be a threat for underground water and aquatic life as well.
\end{abstract}

Keywords: Sewage, fresh water, water bodies, physico-chemical.

\section{Introduction}

Lake is a large inland body of water whereas Pond is a small body of still water or a collection of produce from different sources.

Millions of people all over the world particularly in developing countries are losing their lives every year due to water-borne diseases ${ }^{1}$. About $97 \%$ to earth's water supply is in the ocean which is unfit for human consumption and other uses because of its high salt content. The remaining $2 \%$ is locked in the polar ice caps and $1 \%$ is available as fresh water in rivers, lakes, streams, reservoirs and ground water ${ }^{2}$ which is suitable for human consumption.

Water can be obtained mainly from two sources namely surface water and ground water. Surface water is any water that travels or is stored on top of the ground. This would be the water in rivers, lakes, streams, reservoirs, and even the oceans. Rain water is the purest form of natural water, since it is obtained as a result of evaporation from the surface water. However in its downwards journey through atmosphere it dissolves a considerable amount of industrial gases like $\mathrm{CO} 2, \mathrm{NO} 2, \mathrm{SO} 2$, etc and suspended solid particles both of organic and inorganic ${ }^{3}$ origin. Ponds with water in large quantity for most part of the year are available in Coimbatore and also it has only a very few rivers like Siruvani to supply water. But the quality of water obtained from these ponds is not reliable because it contains suspended matter and number of other impurities ${ }^{4}$.

The main source of ground water is rain water. A major part of rain water is absorbed into the earth. The absorbed water percolates into the earth and goes deep down the earth. Water beneath the surface comprises the next largest store of water. Ground water and soil water together make up about $0.5 \%$ of all water (by volume).

Clean water is needed for drinking, cooking, bathing, washing, for sanitary disposal of domestic and human waste, for agriculture, for industrial processes as in production of material such as steel and other metals, paper, textiles, beverages, rubber, plastics, lather ${ }^{5}$ etc. Water is one of the most essential substances needed to sustain human life, animals and plants. Although we as human beings recognize these facts but disregard it by polluting its different sources.

Today the accelerated pace of development, rapid industrialization and population density have increased water pollution at an alarming rate by adding numerous waste to water reservoirs ${ }^{6}$.

Water pollution is the alteration in physical, chemical and biological characteristics of water which may cause harmful effects on man and aquatic biota. Water pollution actually represents the state of deviation from the pure condition where by its normal function and properties are affected. Any shift in the naturally dynamic equilibrium existing among environmental segments i.e. hydrosphere, lithosphere, atmosphere or sediments give rise to the state of water pollution.

Aims and Objectives of the Study are:

\footnotetext{
${ }^{1}$ Sing A, Jolly SS, Devi P, Bansal BC, Singh SS. Indian J Med Res, 1962; 50:387-398

2 Kanwar JS, Mehta KK. Indian J Agric Sci, 1968; 38:881-886.

${ }^{3}$ Jolly SS, Singh ID, Prasad S, Sharma R, Singh BM, Mathur OC. Indian J Med Res, and 1969; 57:1333-1346

${ }^{4}$ Kaufman DB, DiNicola W, McIntosh R. Am J Dis Child. 1970; 119: 374-376

${ }^{5}$ Tare V, Gupta S, Bose P, et al. Journal of the Air \& Waste Management Association, and 2003; 53:976-982.

${ }^{6}$ Mahapatra MK, Mishra HS. Poll Res, 2005; 24(4): 863-865.
} 
(1) To assess the water quality of pond, through analysis of some selected water quality parameters.

(2) To compare the result with standard limits.

(3) To determine environmental condition of the pond and predict pollution status.

\subsection{Study Area}

\section{Material And Methods}

Samples of water from Vaalankulam at Ukkadam were taken on 6-1-2014 (Monday). One part of this pond has been undergone with some maintenance activities often and used for fishing purposes. But the other part is disposed off with sewage from the nearby sources like hospital and industries.

\section{Sampling}

Samples were collected in $250 \mathrm{ml}$ sampling water(glass) for DO and BOD, also sample were collected in plastic bottle for other physiochemical parameters, pre-cleaned by washing with non-ionic detergents, rinsed in tap water. Before sampling, the bottles were rinsed three times with sample water before being filled with the sample. The actual samplings were done midstream by plunging (immersing) each sample bottle at approximately $20-30 \mathrm{~cm}$ below the water surface, projecting the mouth of the container against the flow direction. The samples were then transported in cooler boxes.

\section{Physicochemical analysis}

Water samples from above mentioned sites were collected and brought to laboratory for analysis. All field meters and equipments were checked and calibrated according to the manufactures specification. During the study, the experiments were carried out at room temperature $32^{\circ} \mathrm{C}$ and following parameters were investigated by usual methods.

1. $\mathrm{pH}$ using $\mathrm{pH}$ meter

2. Acidity and Alkalinity was determined by visual titration method using methyl orange and phenolphthalein as indicator

3. Chlorides using argentometric method

4. Total Dissolved Solids using TDS meter

5. Sulphates using standard colorimeter

6. Total Hardness using complex-metric method

7. Temporary and Permanent hardness using complex-metric method

8. Dissolved Oxygen (DO) using titration

9. Biochemical Oxygen Demand (BOD) using BOD incubator method

10. Chemical oxygen demand (COD) using reflux method

\begin{tabular}{|l|l|l|l|l|}
\hline S No. & Parameters & Standard value & Sample 1 & Sample 2 $^{*}$ \\
\hline 1 & pH & $7.0-8.5$ & 8.6 & 6.9 \\
\hline 2 & Acidity & - & 0 & 0 \\
\hline 3 & Alkalinity & 250 & 70 & 70 \\
\hline 4 & DO & 6 & 30 & 8 \\
\hline 5 & Chlorides & 250 & 230.84 & 146.44 \\
\hline 6 & Sulphates & 200 & 9036.98 & 8043.04 \\
\hline 7 & TDS & 500 & 725.9 & 644.3 \\
\hline 8 & Total hardness & 300 & 175 & 270 \\
\hline 9 & Permanent hardness & - & 110 & 50 \\
\hline 10 & Temporary hardness & - & 65 & 50 \\
\hline 11 & BOD & $1.6-9.2$ & 14 & 0 \\
\hline
\end{tabular}

*(Sample 1 refers to less polluted water used for fishing purpose in Vaalankulam)

*(Sample 2 refers to more polluted water where the city sewage is disposed near the residential area)

\section{Discussion}

The study reveals that the pond which is being used for fisheries (sample 1$)^{*}$ for a longtime is rich in sulphate content which is carcinogenic in nature. So the fishes consumed are prone to biomagnifications and thereby bioaccumulation occurs in the people consuming the fishes in and around the Coimbatore city .So this part of the pond requires immediate treatment to prevent bioaccumulation and biomagnifications. But the other part of the pond which is not being maintained and more polluted has low sulphate content and many suitable parameters of drinking water; it can be used for various domestic purposes and fisheries if treated and maintained. 


\section{Results}

The present study was undertaken to study the physio-chemical quality of water samples which were taken from Vaalankulam. The results revealed that the values of sulphate were found to cross the standard limits in water samples. Despite excess of sulphate concentration in the water the other parameters satisfy the standard values and it can be used for various domestic purposes. If not at least can be used for economical purpose like fisheries, if sewage is not disposed in it. The study is mainly concerned about the well being of the people in and around the Coimbatore city.

\section{References}

[1]. Sing A, Jolly SS, Devi P, Bansal BC, Singh SS. Indian J Med Res, 1962; 50:387-398.

[2]. Kanwar JS, Mehta KK. Indian J Agric Sci, 1968; 38:881-886.

[3]. Jolly SS, Singh ID, Prasad S, Sharma R, Singh BM, Mathur OC. Indian J Med Res, and 1969; 57:1333-1346

[4]. Kaufman DB, DiNicola W, McIntosh R. Am J Dis Child. 1970; 119: 374-376.

[5]. Tare V, Gupta S, Bose P, et al. Journal of the Air \& Waste Management Association, and 2003; 53:976-982.

[6]. Mahapatra MK, Mishra HS. Poll Res, 2005; 24(4): 863-865. 